University of Nebraska - Lincoln

DigitalCommons@University of Nebraska - Lincoln

\title{
Beet Armyworm (Lepidoptera: Noctuidae) Host Plant Preferences for Oviposition
}

S. M. Greenberg

Kika de la Garza Subtropical Agricultural Research Center, sgreenberg@weslaco.ars.usda.gov

T. W. Sappington

Texas Agricultural Experiment Station

T.-X. Liu

Texas Agricultural Experiment Station

Follow this and additional works at: https://digitalcommons.unl.edu/usdaarsfacpub

Part of the Agricultural Science Commons

Greenberg, S. M.; Sappington, T. W.; and Liu, T.-X., "Beet Armyworm (Lepidoptera: Noctuidae) Host Plant Preferences for Oviposition" (2002). Publications from USDA-ARS / UNL Faculty. 719.

https://digitalcommons.unl.edu/usdaarsfacpub/719

This Article is brought to you for free and open access by the U.S. Department of Agriculture: Agricultural Research Service, Lincoln, Nebraska at DigitalCommons@University of Nebraska - Lincoln. It has been accepted for inclusion in Publications from USDA-ARS / UNL Faculty by an authorized administrator of DigitalCommons@University of Nebraska - Lincoln. 


\title{
Beet Armyworm (Lepidoptera: Noctuidae) Host Plant Preferences for Oviposition
}

\author{
S. M. GREENBERG, ${ }^{1}$ T. W. SAPPINGTON, M. SÉtAMOU, ${ }^{2}$ and T. -X. LIU ${ }^{2}$
}

Integrated Farming and Natural Resources Research Unit, Kika de la Garza Subtropical Agricultural Research Center, 2413 East Highway 83, Weslaco, TX 78596

\begin{abstract}
Environ. Entomol. 31(1): 142-148 (2002)
ABSTRACT Beet armyworm, Spodoptera exigua (Hübner), oviposition preferences were determined on five host plants: cabbage (Brassica oleracea capitata L.), cotton (Gossypium hirsutum L.), bell pepper (Capsicum annum L.), pigweed (Amaranthus retroflexus L.), and sunflower (Helianthus annuus L.) in no-choice, two-choice, and five-choice tests. Tests were conducted in the laboratory, greenhouse, and field cages. Oviposition preferences were compared on the basis of two measurements, the proportion of eggs laid on the plants to total that were deposited, and the oviposition preference index defined as [ (number of eggs laid on the plant) - (number of eggs laid on the cage) ] $\times 100$ /total number of eggs laid. The proportion of eggs laid on the plants to total that were deposited was highest for pigweed and lowest for cabbage in all tests. Beet armyworm females were significantly deterred from laying eggs on cabbage and sunflower, while pigweed and cotton elicited a positive oviposition preference. Pepper tended to be neutral or slightly unattractive. Apparent interactions among plant species in choice tests produced measurable shifts in oviposition preference. Most notably, female response to pepper was enhanced in the presence of cotton or pigweed. Egg masses laid on the plants contained significantly higher numbers of eggs than those laid on the surface of the cage, except in the case of cabbage leaves. Knowledge of hierarchies of host plant oviposition preference by beet armyworm females will be useful in understanding the population dynamics of this important agricultural pest, and for developing effective monitoring and management strategies.
\end{abstract}

KEY WORDS Spodoptera exigua, beet armyworm, host plants, oviposition preference

THE BeET ARMYWORM, Spodoptera exigua (Hübner), is a serious pest of numerous wild and cultivated plants throughout the world. It is a cosmopolitan species that attacks $>90$ plant species in North America, many of which are crop plants (Pearson 1982). Insecticides directed against the larval stage of beet armyworm are the primary method of control, but high tolerance to most insecticides and associated environmental problems may jeopardize their continued use (Brewer and Trumble 1991, Burris et al. 1994, Sparks et al. 1996, Mascarenhas et al. 1996, 1998). Therefore, control programs should not rely solely on insecticides, and alternative control strategies that prevent the development of population outbreaks or reduce the cost of management are needed.

Development of effective alternative strategies for managing the beet armyworm will require a thorough knowledge of the biological interactions of the insect and its hosts. A very important component of such

This article reports the results of research only. Mention of a commercial or proprietary product does not constitute an endorsement or a recommendation for its use by USDA.

${ }^{1}$ E-mail: sgreenberg@weslaco.ars.usda.gov.

${ }^{2}$ Texas Agricultural Experiment Station, 2415 East Highway 83, Weslaco, TX 78596. interactions is that of host preference for oviposition, but information on this subject with respect to $S$. exigua is limited. Several studies have addressed $S$. exigua oviposition behavior in no-choice situations (Mitchell and Heath 1985, Smits et al. 1986, Yoshida and Parrella 1991, Sappington et al. 2001, Tisdale and Sappington 2001), but information is needed regarding relative preferences when in the presence of multiple potential hosts. Our objectives were to evaluate beet armyworm oviposition preferences and egg deposition patterns among selected crop and weed species common to the Lower Rio Grande Valley of Texas.

\section{Materials and Methods}

Host Plants and Experimental Conditions. Five plant species were used in the study: cabbage (Brassica oleracea capitata L.) (Earliana, W. Atlee Burpee, Warminster, PA), cotton (Gossypium hirsutum L.) (DPL-50, Delta Pine Land, Scott, MS), bell pepper (Capsicum annuum L.) (Capistrano, Peto Seed, Saticoy, CA), pigweed (Amaranthus retroflexus L.), and wild sunflower (Helianthus annuus L.). Pigweed and sunflower seeds were collected from local wild plants the previous fall (1999). These plants were selected 
based on their importance as cultivated crops (cabbage, cotton, and pepper) or their wide distribution as weeds (pigweed and wild sunflower) in the Lower Rio Grande Valley of Texas, as well as their known associations with the beet armyworm. Plants were grown in $30-\mathrm{cm}$ pots in sunshine mixture \#1 (SunGro Horticulture, Elma, MB, Canada) for laboratory and greenhouse tests, but were also planted directly in the soil in field cages. For greenhouse and field tests, we used intact 30- to 35-d-old plants; in laboratory tests we used leaves excised from the central canopy of those plants. Laboratory and greenhouse experiments were conducted at $26 \pm 2^{\circ} \mathrm{C}$ and a photoperiod of 12:12 (L:D) h. The greenhouse tests were conducted in January and February and the photophase was lengthened to $12 \mathrm{~h}$ by artificial lighting.

Insects and Measures of Oviposition Preference. Beet armyworm adults were obtained from a laboratory colony maintained at the Kika de la Garza Subtropical Agricultural Research Center in Weslaco, TX. They had been reared exclusively on a soybean-wheat germ diet (Shaver and Raulston 1971) for $\approx 3 \mathrm{yr}$. Spatial placement of egg masses on cotton plants by moths from this same colony was not grossly different than that by wild moths (Sappington et al. 2001). We reasoned that the use of uniform insects reared on a neutral diet would help avoid potentially confounding effects of dietary history on host plant preference.

We measured and compared oviposition preferences of the beet armyworm on various host plants using two different measures. The first measure was the proportion of the total number of eggs laid that were deposited on the plant surface. For this measure a value $>0.5$ was interpreted as an indication the host plant was attractive for oviposition. We also used the oviposition preference index of Grant and Langevin (1995): [ (number of eggs laid on host plant) - (number of eggs laid on cage) ] $\times 100 /$ total number of eggs oviposited. The advantage of the oviposition preference index over a simple ratio is that it has a fixed range of -100 to +100 , so that a negative value indicates oviposition deterrence and a positive value indicates stimulation. Values not significantly different from zero indicate that the plant is neither repulsive nor attractive for oviposition.

No-Choice Tests. Acceptability of leaves for oviposition was examined in the laboratory for each plant species. Leaves were excised near the axil with a razor blade and each leaf petiole was immediately placed in a floral aquapic with hydroponic solution (Aqua-Ponic International, Los Angeles, CA). Excised leaves rooted readily and did not deteriorate under fluorescent lighting (20-W, Vita-Lite, Duro-Test Lighting, Elk Grove, IL) in an incubator. Hydroponic solution was added to the aquapics as necessary. Two leaves of a given host plant were placed in a cylindrical plastic cage ( $25 \mathrm{~cm}$ diameter and $30 \mathrm{~cm}$ high) with a nylonscreen top. A newly emerged female and male were confined in each cage for $5 \mathrm{~d}$. Adults were supplied with a soaked ( $10 \%$ sucrose) cotton ball in a cup for feeding, which was replenished daily. Cages were examined daily to record the numbers of egg masses and eggs laid on the plants and on the walls of the cage. One cage of each plant species was a replication, and there were 16 total replications. Replications were accumulated two at a time in a series of eight repeated experiments.

Acceptability of intact plants for oviposition were similarly examined in the greenhouse. Two pots, each containing two plants of a given species, were placed in a screened cage $(1 \mathrm{~m}$ long by $0.6 \mathrm{~m}$ wide by $1 \mathrm{~m}$ high). Five 2-d-old mated females were released in each cage and allowed to oviposit for $3 \mathrm{~d}$. Four cups, each containing a cotton ball soaked with $10 \%$ sucrose, were placed in each cage for adult feeding. The number of egg masses laid on the plants and on the cage were recorded daily. One cage containing four plants of a given species was a replication, and there were eight total replications. Replications were accumulated two at a time in a series of four repeated experiments.

Two-Choice Tests. All possible paired combinations of cabbage, cotton, pepper, pigweed, and sunflower were tested, using excised leaves in laboratory and intact plants in greenhouse experiments. In the laboratory study, two excised leaves (in floral aquapics), one leaf of each species of a given combination, were placed in a plastic cage. One cage represented one replication of that combination. Each experiment, consisting of one replication of all possible combinations, was performed at one time, and the experiment was repeated four times.

In the greenhouse tests, each species of a paired combination was represented by two pots, each containing two plants. Thus, each cage contained a total of four pots. One cage of each possible combination was a replication. Each experiment consisted of one replication each of all possible combinations. The experiment was repeated three times.

Numbers of beet armyworm females, and methods of introduction, feeding, and monitoring oviposition were as described for the no-choice laboratory and greenhouse tests. Females were allowed to oviposit for three nights.

Five-Choice Tests. In these tests moths were exposed to all five host species simultaneously. Responses to excised leaves were examined in the laboratory and responses to intact plants were evaluated in the greenhouse and field cages. In the laboratory study, one excised leaf from each of cabbage, cotton, pepper, pigweed, and sunflower were held in floral aquapics in a cylindrical plastic cage as previously described. Male-female pairs of newly emerged moths were placed in the cages and females were allowed to oviposit for three nights. Provision of food for the adults and the types of data recorded were the same as described for the laboratory no-choice tests. One cage containing leaves from five plant species was a replication, and there were 11 replications in all.

In the greenhouse, five pots each containing two plants of a single species, but with each pot containing a different species, were placed in each cage. Five 2-d-old mated female beet armyworms were introduced to each cage and allowed to oviposit for three 


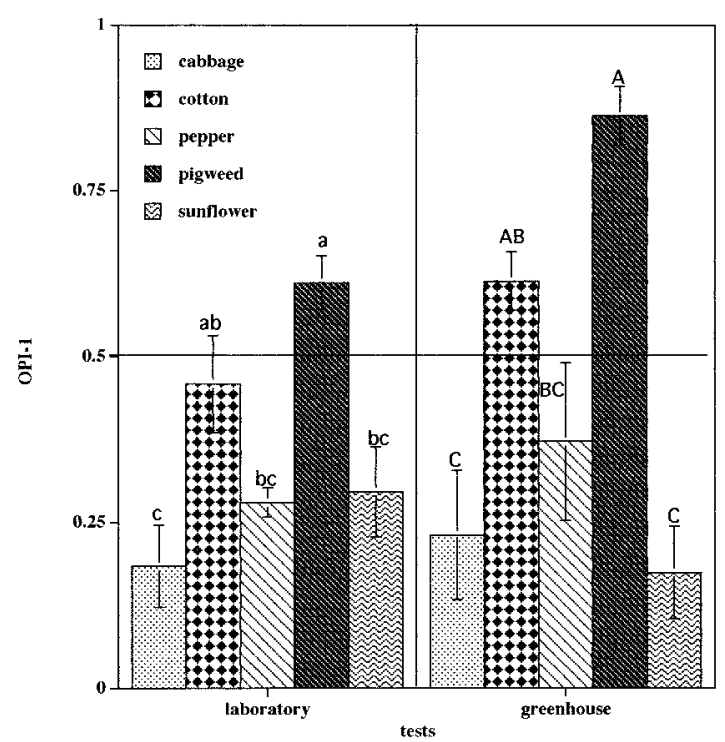

Fig. 1. Mean \pm SE proportions of the total number of beet armyworm eggs laid that were deposited on the surfaces of excised leaves in a floral aquapic (laboratory) or on potted plants (greenhouse) in no-choice tests. Means accompanied by the same letter within tests (lower case, laboratory; upper case, greenhouse) are not significantly different $(P>0.05$; Tukey's HSD).

nights. The feeding of adults and data recorded were the same as described in the greenhouse no-choice tests. Each cage (10 plants) was a replication. There were two cages per experiment, and the experiment was repeated two times.

Five-choice tests were also conducted in walk-in field cages. Three plots $\left(14.0 \mathrm{~m}^{2}\right.$ each $)$ isolated by screen partitions were divided into five randomized rows each three $\mathrm{m}$ long, with each row planted to a single host plant species at 10 plants per row. Plots were planted at $10-\mathrm{d}$ intervals. At $30 \mathrm{~d}$ after planting, 15 2-d-old females were released in each plot. Plants in the plots were checked for egg masses for $3 \mathrm{~d}$ after moths were released.

Statistical Analyses. Statistical analyses were conducted using analysis of variance (ANOVA) and the independent $t$-test function of SYSTAT (Zar 1996, SPSS 1998). One-way ANOVA were performed to detect effects of host plant on the two measures of oviposition preference of beet armyworm females. When experiments were repeated, the homogeneity of variance of the individual experiments was tested before pooling data. If there were no differences, the experiments were pooled. When significant $F$ values were obtained, means were separated using the Tukey's honestly significant difference (HSD) test (no-choice, five-choice tests). In the two-choice tests, means of proportions of the total numbers of eggs laid that were deposited on the plant surfaces and the oviposition preference indices for each combination were compared with paired $t$-tests. Proportion data were arcsine-square root transformed before statisti- cal analyses (Sokal and Rohlf 1994). However, results appearing in the text and tables are presented as backtransformed data. The oviposition index of Grant and Langevin (1995) was considered significantly different from zero if the $95 \%$ confidence interval did not span zero.

Specimens of beet armyworm were deposited in the insect collection of the Texas Agricultural Experiment Station, Weslaco, TX (voucher \# 99-05-01).

\section{Results}

No-Choice Tests. In the laboratory tests using excised leaves, the proportion of eggs laid on the plant surface was highest for pigweed (0.612) and lowest for cabbage (0.184) $(F=8.7 ; \mathrm{df}=4,75 ; P=0.001)$ (Fig. $1)$. The only positive response was to pigweed. In the greenhouse tests, we observed a similar trend except that cotton elicited a positive response in addition to pigweed. Overall, the proportions of eggs laid on the plants in the greenhouse were higher than in the laboratory tests, except in the case of sunflower. Mean proportions of eggs laid on plants in greenhouse tests followed the hierarchy of pigweed $>$ cotton $>$ pepper $>$ cabbage $>$ sunflower $(F=12.7 ; \mathrm{df}=4,35 ; P=$ 0.038 ) (Fig. 1). Significantly negative oviposition preference index values (Grant and Langevin 1995) (Fig. 2 ) indicated that beet armyworm females were deterred from laying eggs on cabbage, pepper, and sunflower in the laboratory and the greenhouse tests.

Two-Choice Tests. The oviposition response of beet armyworm females to the host leaves or plants pre-

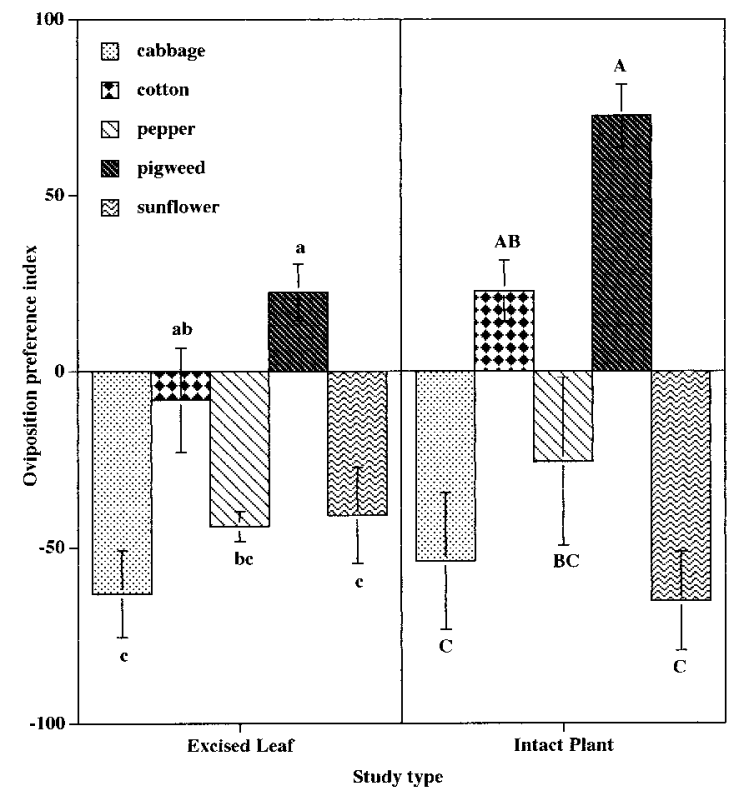

Fig. 2. Mean $\pm \mathrm{SE}$ oviposition preference index values (Grant and Langevin 1995) for excised leaves in a floral aquapic (laboratory) or for potted plants (greenhouse) in no-choice tests. Means accompanied by the same letter within tests (lower case, laboratory; upper case, greenhouse) are not significantly different $(P>0.05$; Tukey's HSD). 


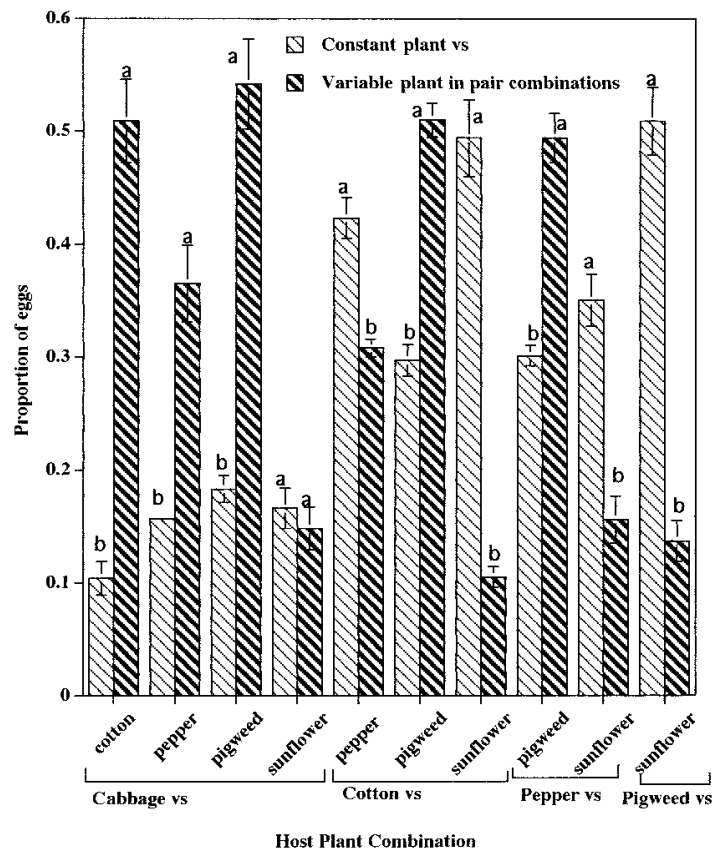

Fig. 3. Mean \pm SE proportion of beet armyworm eggs laid that were deposited on the surfaces of excised host plant leaves in floral aquapics when presented with different hostpair combinations in the laboratory. Means accompanied by the same letter in paired combinations are not significantly different $(P>0.05$; independent $t$-test $)$.

sented in paired combinations in the laboratory or greenhouse was consistent with results observed in the no-choice tests (Figs. 3 and 4). Females preferred to oviposit on pigweed compared with other plants. The proportions of the eggs laid by beet armyworm females on cotton plants were significantly higher than on cabbage and sunflower in both tests (Figs. 3 and 4), and on pepper in the laboratory test (Fig. 3). Oviposition on pepper was higher than that on cabbage or sunflower. Oviposition on cabbage and sunflower did not differ significantly $(P=0.517)$. In some cases, for instance when cabbage was paired with sunflower (laboratory and greenhouse tests, Figs. 3 and 4) and when pepper was paired with sunflower (greenhouse tests, Fig. 4), more eggs were laid on the cage screen than on both plant types combined, further emphasizing the low acceptability of those host plants.

Positive oviposition preference index values indicate that pigweed significantly stimulated oviposition (Fig. 5). Oviposition preference index values for cotton were consistently positive, but were significantly greater than zero only when paired with pigweed (Fig. $5)$. In contrast, oviposition preference index values for cabbage and sunflower were significantly negative in all cases. Response to pepper was significantly reduced when it was paired with cabbage or sunflower (Fig. 5). Also, cotton was more attractive for oviposition when it was presented with pigweed than when it was presented with cabbage (Fig. 5). Thus, inter-

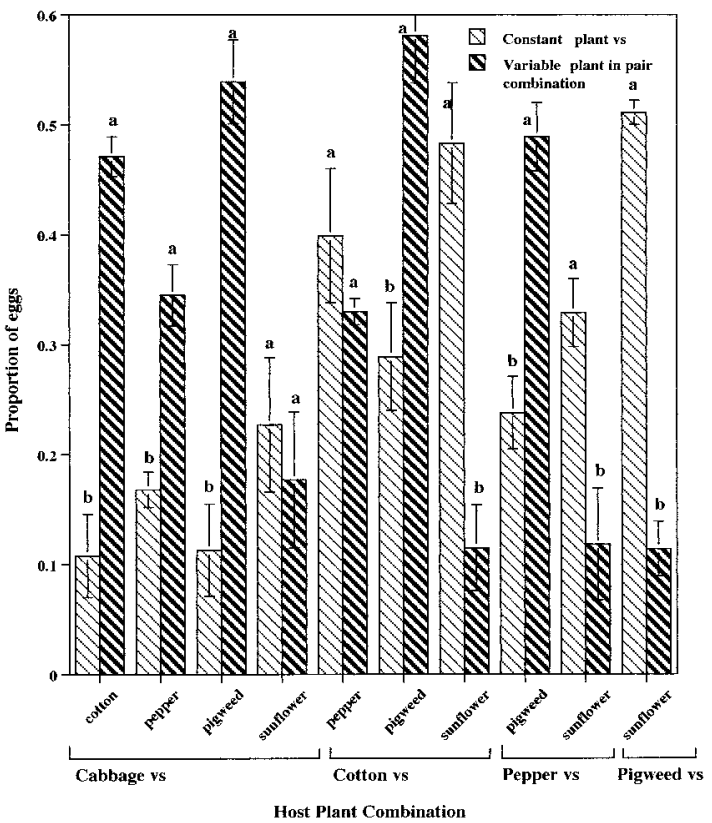

Fig. 4. Mean \pm SE proportion of the total number of beet armyworm eggs laid that were deposited on potted plants when presented with different host-pair combinations in the greenhouse. Means accompanied by the same letter in paired combinations are not significantly different $(P>0.05$; independent $t$-test).

actions among plant types in a pair influenced oviposition behavior.

Five-Choice Tests. When simultaneously presented with all five plant species, oviposition preference for pepper was similar to that for cotton and pigweed (Fig. 6; Table 1). The respective proportions of total eggs laid that were deposited on these three plants were not significantly different, but were significantly higher than the proportions for cabbage or sunflower in laboratory $(F=11.5 ; \mathrm{df}=4,50 ; P=0.001)$ and greenhouse tests $(F=35.7 ; \mathrm{df}=4,15 ; P=0.001)$.

In the field-cage tests, the average number of eggs laid per plant on cotton, pigweed, and pepper were not significantly different, but were significantly higher than on cabbage or sunflower (Table 1). These results suggest that the female's perception of pepper is changed positively through the interaction of cues from at least two of the other host plants tested.

Egg Mass Size. There were no significant differences in the numbers of eggs per egg mass deposited on cabbage leaves or on cage walls in either laboratory $(t=0.2, \mathrm{df}=144.8, P=0.84)$ or greenhouse experiments $(t=0.243, \mathrm{df}=15.9, P=0.811)$, or on sunflower leaves compared with those on cage walls in the laboratory tests $(t=0.804, \mathrm{df}=170.0, P=0.422)$. In all other cases, the sizes of egg masses were significantly higher on the plants than on cage walls (Table 2). Egg mass size was significantly greater on pigweed and cotton than on pepper and sunflower in the laboratory tests $(F=5.9 ; \mathrm{df}=4,379 ; P=0.001)$, and significantly greater than on cabbage, pepper, and 


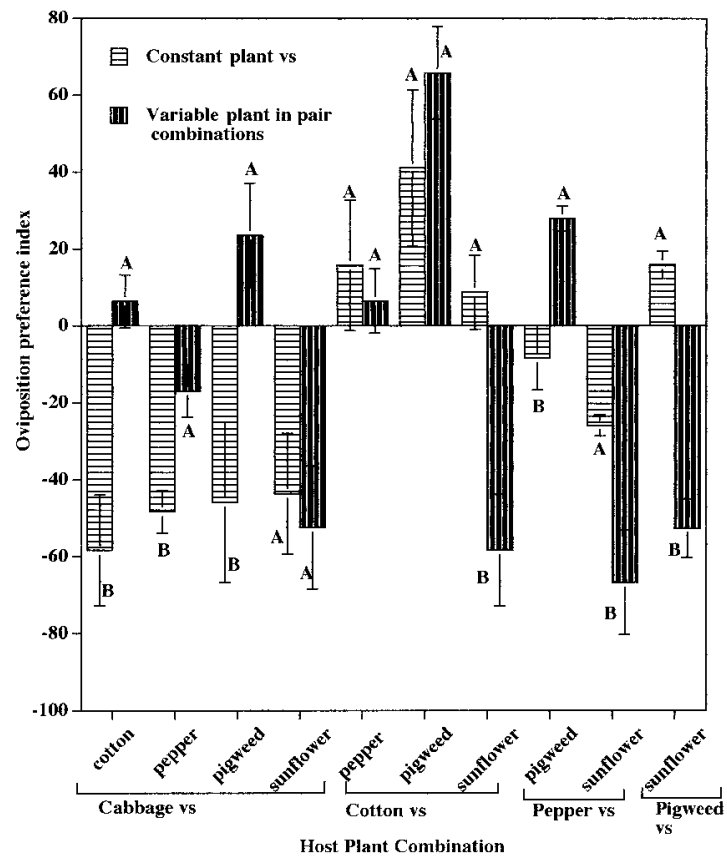

Fig. 5. Mean $\pm \mathrm{SE}$ oviposition preference index values (Grant and Langevin 1995) of beet armyworm for potted plants when presented with different host-pair combinations in the greenhouse. Means accompanied by the same letter in paired combinations are not significantly different $(P>0.05$; independent $t$-test).

sunflower in the greenhouse tests $(F=14.7 ; \mathrm{df}=4,50$; $P=0.002)$ (Table 2).

\section{Discussion}

The beet armyworm's polyphagous nature has been interpreted as evidence that the moth oviposits indiscriminately on any available plant species (Atkins 1960), but our results clearly show that oviposition preferences existed among the five host plants tested. Even when given no choice of host plant, females tended to lay more eggs on the cage screen than on cabbage or sunflower suggesting that cues from these plants were not simply nonstimulating, but were less attractive than the wire screen. In contrast, pigweed and to a lesser extent cotton in potted plant experiments were significantly attractive for beet armyworm oviposition. Pepper tended to be neutral or slightly less attractive than the cage.

In general, the hierarchy of preference suggested by the no-choice tests was reflected in the results of the two-choice and five-choice tests. The highest proportion of total eggs laid were on pigweed, followed by cotton and pepper. Sunflower and cabbage were clearly less attractive. However, it is clear that oviposition preference and behavior are somewhat contextdependent. The female's perception of pepper in an isolated context is changed positively through the interaction of cues from either cotton or pigweed, or both. It is possible that negative cues from both sun-

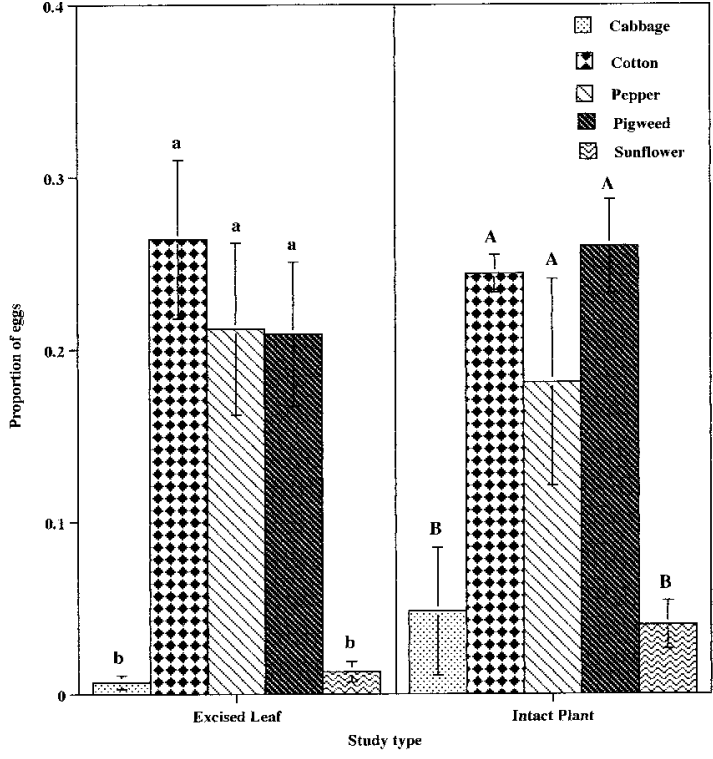

Fig. 6. Mean \pm SE proportions of the total number of beet armyworm eggs laid that were deposited on excised leaves of five different host plants in floral aquapics and presented simultaneously or on potted plants of five different hosts presented simultaneously. Means accompanied by the same letter within tests (lower case, laboratory; upper case, greenhouse) are not significantly different $(P>0.05$; Tukey's HSD).

flower and cabbage combined made pepper more attractive, but this seems unlikely given the apparent lack of such a negative effect on pepper's oviposition preference index values in the pairwise greenhouse trials compared with its oviposition preference index value in isolation.

The nature of the host plant cues recognized by beet armyworm females is unknown, but could be chemical, tactile, visual, or some combination. Differences in oviposition response to isolated leaves compared with whole plants suggest that tactile cues (which should be the same in either experiment) are less important than chemical or visual cues in the case of cotton, pigweed, and sunflower, but this may not be the case with cabbage. Dependence of differential changes in oviposition behavior toward a given host on the species of a nearby host suggests that chemical cues maybe more important than tactile cues, and

Table 1. Mean \pm SE numbers of egg masses and eggs oviposited on selected host plants exposed to beet armyworm females in a field cage five-choice test

\begin{tabular}{lccr}
\hline \hline Host plant & $n$ & Egg masses per plant & Eggs per plant \\
\hline Cabbage & 60 & $0.92 \pm 0.46 \mathrm{~b}$ & $29.6 \pm 13.6 \mathrm{~b}$ \\
Cotton & 60 & $1.45 \pm 0.16 \mathrm{ab}$ & $156.8 \pm 36.8 \mathrm{a}$ \\
Pepper & 60 & $1.26 \pm 0.33 \mathrm{ab}$ & $121.8 \pm 29.8 \mathrm{a}$ \\
Pigweed & 60 & $1.8 \pm 0.46 \mathrm{a}$ & $147.5 \pm 30.5 \mathrm{a}$ \\
Sunflower & 60 & $0.33 \pm 0.33 \mathrm{c}$ & $8.3 \pm 7.1 \mathrm{~b}$ \\
\hline
\end{tabular}

Means within a column and followed by the same letter are not significantly different (Tukey's HSD, $P>0.05$ ). $n$, number of plants. 
Table 2. Mean \pm SE numbers of beet armyworm eggs per egg mass on respective plant and cage surfaces for selected host plants in no-choice tests

\begin{tabular}{|c|c|c|c|c|}
\hline \multirow{3}{*}{ Host } & \multicolumn{4}{|c|}{ Mean \pm SE no. of eggs per egg mass } \\
\hline & \multicolumn{2}{|c|}{ Laboratory tests (on excised leaves) } & \multicolumn{2}{|c|}{ Greenhouse tests (on intact plants) } \\
\hline & Leaves $(n)$ & Cage & Plants $\left(n_{1}\right)$ & Cage \\
\hline Cabbage & $54.0 \pm 4.0 \mathrm{abA}(74)$ & $53.3 \pm 4.5 \mathrm{aA}$ & $28.9 \pm 3.5 \mathrm{cA}(13)$ & $28.9 \pm 1.4 \mathrm{bA}$ \\
\hline Cotton & $68.2 \pm 4.7 \mathrm{aA}(100)$ & $39.7 \pm 3.0 \mathrm{bB}$ & $96.4 \pm 9.3 \mathrm{aA}(10)$ & $53.4 \pm 1.9 \mathrm{aB}$ \\
\hline Pepper & $46.6 \pm 4.1 \mathrm{bA}(50)$ & $26.6 \pm 2.4 \mathrm{bB}$ & $66.2 \pm 7.2 \mathrm{bA}(12)$ & $49.5 \pm 1.8 \mathrm{aB}$ \\
\hline Pigweed & $66.6 \pm 4.3 \mathrm{aA}(90)$ & $48.6 \pm 4.7 \mathrm{abB}$ & $86.3 \pm 11.9 \mathrm{aA}(10)$ & $50.6 \pm 2.6 \mathrm{aB}$ \\
\hline Sunflower & $46.0 \pm 3.5 \mathrm{bA}(70)$ & $41.5 \pm 4.3 \mathrm{abA}$ & $37.7 \pm 3.9 \mathrm{bcA}(10)$ & $25.2 \pm 2.0 \mathrm{bB}$ \\
\hline
\end{tabular}

Means within a column followed by the same lower case letter are not significantly different (Tukey's HSD, $P>0.05$ ). Pairs of means within a row (by test) followed by the same upper case letter are not significantly different $(t$-test. $P>0.05) . n$ - number of leaves, $n_{1}$ - number of plants.

perhaps more important than visual cues, in host plant discrimination by females. However, experiments designed to specifically test these hypotheses will be necessary to dissect the relative importance of potential cues influencing oviposition preference in these different contexts.

Interestingly, host plant choice is not the only behavioral adaptation of females related to placing offspring on suitable host plants. The average number of eggs per egg mass depended on the host plant, and followed the same hierarchical ordering as host plant preference. The difference between egg mass size on potted cabbage and that on potted cotton or pigweed was 2.5 - to 3 -fold. In parallel studies, we found that indices of beet armyworm developmental efficiency from larva to adult depended on host plant, also in the same hierarchical order. For example, development on pigweed from first instar to pupa was several days faster, and required less gram-intake of leaf tissue than development on cabbage (Greenberg et al. 2001). Thus, it appears that the host plant oviposition preference hierarchy of beet armyworm females corresponds to nutritive value of the potential hosts, and that egg mass size can be modified to reflect the perceived suitability of a host that a female has selected for oviposition. Host-dependent variation of egg mass size or clutch size has been reported in other insects (Van Leerdam et al. 1984, Grant and Langevin 1995). Sappington et al. (2001) reported 29\% fewer eggs per egg mass oviposited by beet armyworm on cotton compared with that on pigweed in field cage tests, whereas the results reported herein revealed no differences between these two hosts in isolated leaf and potted-plant experiments. In greenhouse studies, Smits et al. (1986) found that variation in beet armyworm egg mass size did not vary among hosts that included chrysanthemum, tomato, gerbera, and geranium, but that younger chrysanthemums received more eggs than older plants. In our study, plant age was uniform, but plant development may not be equivalent across the species we tested at the chosen age. An important variable yet to be studied is the effect of plant age and phenology on host plant preference and oviposition behavior. For example, physiologically young cotton may be more or less attractive than nearby physiologically old pigweed.
The size of egg masses deposited on the cage screen in our tests reflected the size of egg masses deposited on the corresponding potted host plant in that cage. This is consistent with volatile chemical cues being important in beet armyworm host-dependent oviposition behavior. However, the hierarchical pattern of size of egg masses oviposited on the screen did not correspond to that on the isolated leaves. The hierarchy of egg mass size on isolated leaves followed a similar pattern as that on potted plants, but the differences were of lesser magnitude.

Knowledge of hierarchies of host plant oviposition preference by beet armyworm females will be useful in designing cultural management strategies, which may include trap cropping. Wild and cultivated plant hosts of beet armyworm serve as important reservoirs for populations that subsequently infest other crops. Successful management of these populations, and especially avoidance of severe outbreaks, will require a more complete understanding of beet armyworm ecology in the diverse ecological system within which crops are grown.

\section{Acknowledgments}

We acknowledge the technical assistance of J. Caballero, P. Carreon, and L. Leal. We thank Martin Avila (USDA, ARS, KdlG SARC, Beneficial Insect Research Unit, Weslaco, TX) for assistance in beet armyworm rearing. We are grateful to D. W. Spurgeon and J. Lopez (Areawide Pest Management Research Unit, Southern Plains Area USDA-ARS, College Station, TX) for critical reviews of the manuscript.

\section{References Cited}

Atkins, E. L., Jr. 1960. The beet armyworm, Spodoptera exigua, an economic pest of citrus in California. J. Econ. Entomol. 53: 616-619.

Brewer, M. J., and J. T. Trumble. 1991. Inheritance and fitness consequences of resistance to fenvalerate in Spodoptera exigua (Lepidoptera: Noctuidae). J. Econ. Entomol. 84: 1638- 1644.

Burris, E., J. B. Graves, B. R. Leonard, and C. A. White. 1994. Beet armyworms (Lepidoptera: Noctuidae) in northeast Louisiana: observations on an uncommon insect pest. Fla. Entomol. 77: 454-459.

Grant, G. G., and D. Langevin. 1995. Oviposition deterrence, stimulation, and effect of clutch size of Choristo- 
neura (Lepidoptera: Noctuidae) species by extract fractions of host and nonhost foliage. Environ. Entomol. 24: 1656-1663.

Greenberg, S. M., T. W. Sappington, B. C. Legaspi, Jr., T.-X. Liu, and M. Sétamou. 2001. Feeding and life history of Spodoptera exigua (Lepidoptera: Noctuidae) on different host plants. Ann. Entomol. Soc. Am. 94: 566-575.

Mascarenhas, V. J., B. R. Leonard, E. Burris, and J. B. Graves. 1996. Beet armyworm (Lepidoptera: Noctuidae) control on cotton in Louisiana. Fla. Entomol. 79: 336-343.

Mascarenhas, V. J., J. B. Graves, B. R. Leonard, and E. Burris. 1998. Susceptibility of field populations of beet armyworm (Lepidoptera: Noctuidae) to commercial and experimental insecticides. J. Econ. Entomol. 91: 827-833.

Mitchell, E. R., and R. R. Heath. 1985. Influence of Amaranthus hybridus $\mathrm{L}$. allelochemics on oviposition behavior of Spodoptera exigua and S. eridania (Lepidoptera: Noctuidae). J. Chem. Ecol. 11: 609-618.

Pearson, A. C. 1982. Biology, population dynamics, and pest status of the beet armyworm (Spodoptera exigua) in the Imperial Valley of California. Ph.D. dissertation, University of California, Riverside, CA.

Sappington, T. W., S. M. Greenberg, and R. A. Tisdale. 2001. Location of beet armyworm (Lepidoptera: Noctuidae) egg mass deposition within canopies of cotton and pigweed. Environ. Entomol. 30: 511-516.

Shaver, T. N., and J. R. Raulston. 1971. A soybean wheat germ diet for rearing the tobacco budworm. Ann. Entomol. Soc. Am. 64: 1077-1079.
Smits, P. H., M. van de Vrie, and J. M. Vlak. 1986. Oviposition of beet armyworm on greenhouse crops. Environ. Entomol. 15: 1189-1191.

Sokal, R. R., and F. J. Rohlf. 1994. Biometry: the principles and practice of statistics in biological research. Freeman, San Francisco, CA.

Sparks A. N., Jr., J. W. Norman, Jr., and D. A. Wolfenbarger. 1996. Efficacy of selected insecticides against the beet armyworm, Spodoptera exigua - field and laboratory evaluations, pp. 844-846. In Proc. Beltwide Cotton Conf., National Cotton Council, Memphis, TN.

SPSS. 1998. Systat 8.0, Statistics. SPSS, Chicago, IL.

Tisdale, R. A., and T. W. Sappington. 2001. Realized and potential fecundity, egg fertility, and longevity of laboratory-reared female beet armyworm (Lepidoptera: Noctuidae) under different adult diet regimes. Ann. Entomol. Soc. Am. 94: 415-419.

Van Leerdam, M. B., K.J.R. Johnson, and J. W. Smith, Jr. 1984. Effects of substrate physical characteristics and orientation on oviposition by Eoreuma loftini (Lepidoptera: Pyralidae). Environ. Entomol. 13: 800-802.

Yoshida, H. A., and M. P. Parrella. 1991. Chrysanthemum cultivar preferences exhibited by Spodoptera exigua (Lepidoptera: Noctuidae). Environ. Entomol. 20: 160165.

Zar, J. H. 1996. Biostatistical analysis. Prentice-Hall, Englewood Cliffs, NJ.

Received for publication 11 June 2001; accepted 12 October 2001. 